\title{
Italia y la perspectiva europea: de la «Europa de las Naciones» a la CEE
}

\section{Fernando García Sanz}

Arbor CLXX, 669 (Septiembre 2001), 73-93 pp.

El artículo hace un recorrido por la historia de Italia, trazando a grandes rasgos la evolución de la interpretación de la nación y su relación, mediante la proyección de la política exterior, con el ámbito continental europeo. Desde las propuestas idealísticas sobre Europa durante el Risorgimento hasta el afan europeista de la segunda postguerra, puede detectarse una línea de continuidad que es producto de la convergencia de la evolución de los procesos políticos y culturales del contexto europeo y del particular devenir histórico de la propia Italia durante la época contemporánea.

\section{De la Europa de las naciones a la Europa de las potencias}

El proceso de unificación italiana, el Risorgimento, se llevó a cabo contra Europa. Contra esa Europa que desde el Congreso de Viena pretendía cerrar el continente a la difusión de aquellos principios enarbolados por la revolución francesa y que, precisamente, la experiencia italiana iba a encarnar posiblemente mejor que ninguna otra, sobre todo a partir de los años cuarenta: la revolución y el sentimiento nacional. Aún así, sobre el consenso generalizado en torno a la necesaria 
concatenación de ambos procesos, coexistieron distintas formas de entender los límites de ambos dentro del general movimiento unitario. Tantas como distintas perspectivas desde las que entender la revolución liberal y los distintos perfiles de una futura Nación que partía de un complejo entramado de reinos y regiones históricas y la presencia del Papado y su poder político sobre un amplio territorio de la Italia central ${ }^{1}$.

De la misma forma, se dieron también distintas formulaciones sobre el sentido ulterior de la unidad o, para decirlo con términos de la época, sobre la «misión» de la nación italiana. Un proyecto destacó sobre todos los demás y fue el encabezado por Giuseppe Mazzini. Su idea de nación partía de una concepción romántica de Italia: nación desde siempre basada en una comunidad de territorio, lengua y raza, características que, sin embargo, solo se hacían operativas por compartir una tradición histórica y cultural y, sobre todo y ante todo, por la voluntad de los ciudadanos de ser nación. Es decir, la nación era en realidad un hecho moral expresión de una decisión libre de los ciudadanos. De este modo, Italia se entendía como nación democrática que buscaría la unión con otras naciones democráticas para forjar una Europa de los pueblos alternativa a la Europa de las monarquías. La idea, plasmada en la organización Joven Europa (1834), aunque de vida efímera, «fue el primer organismo europeo fundado sobre el presupuesto de una unión de naciones independientes gobernadas democráticamente» ${ }^{2}$.

Nación y Europa, conceptos antitéticos en el pensamiento y la práctica de los conservadores europeos (con Metternich a la cabeza), encuentran su pleno sentido, su engarce, a partir de las formulaciones de Mazzini: "La nazione non solamente non è fine a se stessa, ma è mezzo, necessario e nobilissimo, per il compimento del fine supremo, e vale a dire l'umanità (...) Ora l'umanità è ancora Europa $»^{3}$. El fin común se alcanzaría mediante el cumplimiento armónico entre las partes de la «misión» que cada pueblo ha recibido de Dios. Aunque el concepto de "misión» no era nuevo entonces (estaba en De Maistre reivindicando la misión de «magistratura» de Francia sobre Europa, y en Schiller sobre la misión alemana como dominadora del mundo), para Mazzini, reclamando para Italia la responsabilidad de iniciar una nueva era de la humanidad, su significado se aleja de la competencia y el enfrentamiento siendo, al contrario, garantía de armonía. Mazzini es -escribió Chabod- «il piú tipico, il più alto rappresentante di una imponente corrente di pensiero europeo che cerca di salvaguardare in pari tempo i diritti delle singoli nazioni e i diritti della maggiore comunità che si chiama Europa ${ }^{4}$. 
Surgían esta y otras iniciativas similares en el contexto de la «Europa de las naciones» que más adelante, sobre todo a partir del último tercio del siglo XIX, se transformaría en la «Europa de los nacionalismos», momento en el que el concepto de nación y su ubicación en el contexto internacional, en Europa, varía sustancialmente.

Libertad y nación habían permanecido estrechamente vinculadas a lo largo del siglo XIX. En una perspectiva ideal, el cumplimiento de las revoluciones nacionales tenía como paisaje último una Europa donde los enfrentamientos no tendrían ya razón de ser y se posibilitaría un escenario de auténtica solidaridad de los pueblos europeos. Pero uno de los movimientos nacionales europeos, aquel que condujo a la unificación de Alemania, rompió de forma brutal esta perspectiva abriendo el período de la política de la fuerza, la política de potencia: «Il pensiero di dare base nazionale agli Stati, e che s'è effettuato per tanta parte durante il secolo ed è stato il meglio dell'opera sua, era pensiero di concordia e di pace. Le nazioni, rizzate di nuovo in piedi, non dovevano nel concetto della nostra generazione, affrontarsi in armi le une e le altre, e guardarsi arcigne e sfidarsi, ma vivere, poiché si era fatto loro giustizia, amiche, e gareggiare nel bene e nel portare ad affetto la maggiore somma di felicità e di virtù di cui sia capace l'uomo. Era un'ideale troppo alto e che credemmo soprattutto troppo prossimo» ${ }^{5}$.

En 1870 Europa se fracturaba. Comenzaba a extenderse la idea de la decadencia de las naciones latinas, cuando en Italia se hacían cálculos sobre la transcendencia y hasta la responsabilidad que se asumía con la ocupación de Roma. Un acontecimiento como la ocupación de Roma en 1870 y su conversión en capital en 1871, dará alas, más que en el pasado, a un interesante debate sobre la «misión» de Italia en el mundo o, lo que es lo mismo, el sentido último del Risorgimento. Roma aunaba dos significados universales por excelencia: la Roma imperial, civilizadora del mundo, y la Roma Papal, cabeza y referencia del cristianismo, seña de identidad fundacional de la propia Europa. Realidades incontrovertibles y demasiado imponentes para no tenerlas en cuenta a la hora de valorar el caracter ideal que suponía la nueva capital de Italia para la construcción y relanzamiento de la nación ${ }^{6}$. Mazzini y Gioberti, cabezas de dos de las corrientes más poderosas del Risorgimento, divergentes en casi todo habían compartido, sin embargo, la aspiración al primado de Italia sobre los pueblos europeos desde una particular idea de Roma. Para el primero desde una Roma mitificada en la terza Roma, la Roma de los pueblos, para el segundo desde la gloria de la Roma cristiana. Pero entrando en el último tercio 
del siglo XIX la situación ha cambiado ostensiblemente: se abría la época de los nacionalismos y los conceptos de «Europa», "misión» y "primado» adquirían un significado distinto, de competencia y de exclusión, en pro de la «nueva divinidad»: «Il singolo Stato lanciato sulla via della conquista» ${ }^{7}$.

\section{Una política de potencia en la Europa de las potencias}

Nadie mejor que Francesco Crispi encarnó en Italia la evolución desde los postulados ideales mazzinianos del Risorgimento. Por decirlo con palabras de Federico Chabod, Crispi se encargará de acentuar en sentido nacionalista la nacionalidad de Mazzini ${ }^{8}$. Insistiendo sobre el origen natural de la nación, se separa en consecuencia del concepto voluntarista mazziniano y risorgimentista en general, aproximándose más al concepto alemán, Volk: una concepción de la nación como grupo étnico ligado a un territorio, anterior y superior a cualquier voluntad singular y colectiva ${ }^{9}$.

Varias veces ministro y Presidente del Consejo, Crispi encabezó una nueva interpretación de la unidad italiana en sintonía también con los nuevos tiempos europeos. La unidad de Italia no podía ser el final sino el inicio del camino, el inicio de una revolución que debía conjugar unificación y desarrollo, «nella ricerca insistita di un nesso stretto tra il processo di unità nazionale e una reale egemonia borghese ancora da costruire ${ }^{10}$. Siendo fuertes en el interior se estaría en grado de cumplir la «misión» de grandeza que la nación imponía. Dicho de otra forma, el Estado tendría el papel definitorio de convertirse en el brazo ejecutor del propio destino «natural», y este no era otro que llegar a ser una gran potencia ${ }^{11}$.

Crispi participó de una gran desconfianza ante el concepto «Europa». Llamó «farsa siniestra» al concierto europeo en una valoración concordante con la opinión de Bismarck, que rechazaba con desprecio cualquier discurso sobre la existencia de la familia europea o sobre los intereses comunes del continente: «he oído siempre la palabra Europa en boca de aquellos que querían algo de otro y no se atrevían a pedirlo en nombre de los propios intereses» ${ }^{12}$. En pro de esos "propios intereses», de la consecución de los objetivos de la política exterior, se podía llegar incluso a sacrificar principios «sacrosantos» del Risorgimento, como admitir la existencia de Austria y, además, llegar a acuerdos con ella $\mathrm{y}$ frenar las reivindicaciones del irredentismo.

No es mi intención llevar a cabo una descripción de la política exterior italiana, pero si creo necesario subrayar aquellos cambios en 
la percepción de la propia Italia y de su aspiración a convertirse en gran potencia europea ${ }^{13}$.

La consecución de Venecia (1866) y la ocupación de Roma, con todas sus implicaciones internacionales, fueron los puntos de atención prioritarios de la acción exterior de los diez primeros años de Gobierno de la Destra. Aun acusados de peligrosa inacción a la hora de atender las exigencias internacionales de Italia, obligados por las dificilísimas circunstancias internas e internacionales se mantuvo una prudente actitud de recogimiento hasta 1882 cuando, ya con la Sinistra en el poder, se hizo entrar a Italia en la lucha inherente al sistema internacional europeo. Mediante los acuerdos con Alemania y Austria nace la Triple Alianza que, no sin altibajos, se convertirá en el eje de la acción internacional de Italia hasta la Primera Guerra Mundial. Este cambio radical fue la consecuencia de dos acontecimientos que afectaban a un importante cambio estratégico en dos de los escenarios en los que, de una forma «natural», Italia había depositado sus expectativas y sobre los que, sin embargo, se operaba sin ser escuchada: los Balcanes (Congreso de Berlín, junio-julio de 1878) y la ocupación francesa de Túnez (Tratado de El Bardo, mayo de 1881) ${ }^{14}$.

Es sabido que Bismarck, quien junto a Cavour más había contribuído a derribar la Europa de Viena, trabajó durante veinte años para ir tapando las grietas de un recreado edificio europeo de hegemonía alemana. Dentro de esa perspectiva, la Triple Alianza se planteaba como un instrumento pacífico, defensivo y así es asumido por Italia. La llegada de Crispi a la Jefatura de Gobierno (1887) cambia esa perspectiva intentando que la Alianza se convierta en un instrumento activo, ofensivo: el soporte y respaldo para elevar a Italia al rango de gran potencia europea. Crispi cambiará tanto los objetivos de Italia como la forma de abordarlos -mayor agresividad y actividad- y los medios que se ponen a disposición. El anhelo pasaba por obtener una presencia colonial, instrumento de las grandes potencias que extendían así sus disputas fuera del continente europeo. Una política exterior ofensiva, tensa, visceralmente antifrancesa se vió dramáticamente frenada y hundida en Etiopia a causa del Desastre de Adua $(1896)^{15}$. La inmediata desaparición política del líder siciliano supuso también el fin de una forma de entender la política, el nuevo Estado italiano y su papel y forma de insertarse en Europa, por culpa del fracaso cosechado en la política exterior, terreno al que Crispi había concedido el primado sobre la política interna.

Sin embargo, las raíces profundas de la derrota de Adua deben buscarse más en la propia genética del colonialismo europeo de finales 


\section{Fernando García Sanz}

del siglo XIX, que en el aireado fracaso de la clase dirigente, de la clase militar, del liberalismo como se repetiría durante el fascismo, o en metahistóricas causas como la su supuesta incapacidad de los italianos para las grandes empresas, su superficialidad o, con caracteres globalizantes, en la decadencia de las naciones latinas en correspondencia con la pujanza de germanos y anglosajones ${ }^{16}$. El racismo fue una de las actitudes más característicamente europeas. De hecho, la prepotencia y la ignorancia sobre el otro con la que se llevaron a cabo algunas acciones coloniales, no solo la italiana, fueron los responsables de desastres como el de Adua. Desde este punto de vista, tanto la crisis colonial como la crisis política que tendría su epicentro en los acontecimientos de 1898, crisis que debate el futuro del sistema liberal entre reacción y reforma, lejos de aparecer como una anomalía se insertan perfectamente en el cuadro, sea político o sea colonial, de la Europa del cambio de siglo.

Pero en cuanto al racismo europeo, a la distinción clásica entre Europa y el resto del mundo se añade con fuerza una distinción «moderna» que consiste en la jerarquización racial entre los propios europeos. En realidad, a la altura de finales de siglo, la diatriba sobre las razas formaba ya parte del «ambiente» y llegó a ser un lugar común manejado todavía a principios del siglo XX como instrumento justificador de los diversos nacionalismos, que se traducían en la lucha por la preminencia en Europa y en el combate imperialista. Para algunos nacionalismos, el principio de nacionalidad era visto como un a priori impuesto por una supuesta objetividad natural, por datos de hecho étnicos, geográficos y lingüisticos preexistentes y condicionantes. Crispi nunca llegó a identificar ese a priori con el factor racial, pero otros coetaneos suyos sí lo hicieron subsumiendo la idea de nación en la de estirpe ${ }^{17}$.

\section{La Europa de latinos y germanos, ¿decadencia de Italia?}

La incontestable irrupción del nuevo Imperio alemán en el escenario europeo significó en primer lugar el hundimiento de la hasta entonces potencia hegemónica en el continente de una forma tal que, quizás por lo inesperado, dió pábulo al arraigo de concepciones racistas en torno a la historia de Europa o confirmó las ya existentes desde años atrás. Ya en el último tercio del siglo XIX, no resultaba una novedad que los pueblos latinos fuesen analizados como la demostración no ya de la decadencia sino de la degeneración de la raza origen de los europeos, la raza aria, producto fundamentalmente de su mezcla bio- 
Italia y la perspectiva Europea:....

lógica. En este sentido, había alcanzado gran difusión el libro del Conde de Gobineau Essai sur l'inégalité des races humaines ${ }^{18}$ donde establecía una taxonomía de la raza blanca europea en la que franceses, italianos y españoles aparecían en los últimos lugares por contener el menor porcentaje de sangre aria por culpa, a su vez, de las mezclas que históricamente habrían contaminado su pureza ${ }^{19}$. Dirige su atención a España para describir la «degeneración de un pueblo», usando para ello términos profusamente utilizados sobre todo en el último cuarto del siglo: «Un gobierno es sobre todo malo cuando el principio del cual ha surgido, dejándose viciar, cesa de ser sano y vigoroso como al comienzo. Tal fue la suerte de la monarquía española ${ }^{20}$. Por si esto fuera poco, los españoles no solo no habrían ganado nada mezclándose con los indios de América sino que ello habría contribuído a la degeneración de los propios españoles, ya «contaminados» por la influencia árabe ${ }^{21}$. Aún así, serían los italianos los más «degenerados» de Europa a los que solo les concede el primado de la «belleza» frente al resto de los pueblos europeos: «Entre estos mismos pueblos (de raza blanca), la desigualdad se descubre todavía entre los diferentes grupos, aunque en un grado inferior, así por lo que respecta a la fuerza como a la belleza. Los italianos son más bellos que los alemanes y que los suizos, más bellos que los franceses y que los españoles. Igualmente los ingleses presentan un caracter de belleza corporal superior al de las naciones eslavas. En cuanto a la fuerza del puño, los ingleses aventajan a todas las demás razas europeas; al paso que los franceses y los españoles poseen una capacidad superior de resistencia a la fatiga» ${ }^{22}$.

La influencia de las ideas de Gobineau fue muy grande en la Europa de la época pero particularmente en la Alemania guillermina de la última década del siglo donde, en general, arraigaron con mayor fuerza que en ningún otro país europeo las teorías racistas que crecían al calor de la exasperación del nacionalismo y de las rivalidades imperialistas. Uno de los racistas más destacados de finales del siglo XIX $\mathrm{y}$ principios del XX, wagneriano y precursor del nazismo, Houston Stewart Chamberlain, recogió y radicalizó los planteamientos de Gobineau pasados ya por el tamiz de las teorías de Darwin ${ }^{23}$. Así, la supuesta decadencia de algunas naciones, la objetiva diferencia entre las naciones europeas, no sería otra cosa que la evidente demostración de la degeneración etnica de algunas de ellas. El positivismo vino a cimentar en buena medida el debate sobre la influencia de la raza, con explicaciones de rango antropológico y en Italia la escuela de Cesare Lombroso fue su mejor intérprete: «Los estudios y libros que incan- 


\section{Fernando García Sanz}

sablemente publicaron Lombroso y su círculo pretendían asentar una nueva ciencia que, partiendo de la medicina y la antropología, resolviera los problemas de las ciencias sociales» ${ }^{24}$. Es en este contexto que se desarrollaron algunos trabajos que vinieron a dar razón en Italia al debate sobre la jerarquización de las razas en Europa.

Es el caso de Guglielmo Ferrero y su libro L'Europa giovane ${ }^{25}$, en el que atendiendo a factores étnicos presentaba una tesis sobre la jerarquización europea desde un punto vista no muy distinto al que realizaría Lord Salysbury en 1898 con su discurso sobre las «naciones moribundas» o la postura que sobre el primado anglosajón representaban las tesis de su ministro de Colonias, J. Chamberlain. Sin embargo, la postura de Ferrero, más conocido mundialmente por su monumental obra dedicada a la historia del Imperio Romano, entronca más desde mi punto de vista con las circunstancias políticas y sociales de la Italia de su tiempo porque, en efecto, como subrayan los Peset «La escuela lombrosiana, con sus afirmaciones y sus seguidores, defiende una ideología y unos principios en un momento determinado, en la alborada nueva y fresca del Risorgimento italiano». Los miembros más destacados de la escuela Lombrosiana (Sighele, Garofalo, Ferri, Ferrero, Roncoroni, Carrara) se sitúan en el entorno del Partido Socialista Italiano, del Partido Radical o incluso, como Sighele, en la órbita de lo que será el partido nacionalista. Fuerzas anti-sistema todavía a finales de siglo, profundamente críticas con la forma de nación triunfante del Risorgimento a la que llegan a considerar semi-legítima por mantener al margen del protagonismo político y social de Italia a la mayor parte del país. Es en este sentido y desde esta óptica ideológica que la experiencia italiana aparece como un fracaso ${ }^{26}$. Lejos de explicaciones racistas de la historia («le spiegazioni per influsso di razza, fondate come sono su concetti causalistici e naturalistici, si convertono sempre in mitologia», escribirá Croce $^{27}$ ), el debate sobre la operatividad explicativa de la jerarquización racial de Europa, en realidad viene a poner de manifiesto los anhelos ideológico-políticos del país y las críticas contra lo que se consideran excesos del positivismo y, en concreto, de la escuela lombrosiana. Se proponen causas históricas, políticas y sociales, para explicar determinadas situaciones que se consideraban contingentes, coyunturales. Así, desde distintos puntos de vista, los trabajos del meridonalista republicano Napoleone Colajanni, del antropólogo y anticlerical Giuseppe Sergi o algunas actuaciones públicas del radical Francesco Saverio Nitti ${ }^{28}$. Así, escribría este último en 1903, «Io credo che nessuna cosa sia più stolta quanto ammettere con leggerezza che ci sia, che ci deva essere una decadenza inevitabile delle razze latine. 
Italia y la perspectiva Europea:....

Io penso anzi che non solo non ci sarà decadenza, ma che i paesi latini siano destinati ad avere un'azione sempre più grande» ${ }^{29}$.

\section{Una nueva nación en la Europa de las alianzas}

La salida de la crisis de fin de siglo en Italia se presentó como una alternativa distinta a la manera de entender el Risorgimento que había protagonizado los ultimos años del siglo XIX. El cambio era profundo pues, rechazando la alternativa reaccionaria y represiva, no se intentaba solo procurar el alargamiento del sistema liberal y sus instituciones hacia las fuerzas que podemos denominar populares (radicales, católicos y socialistas), sino que se trataba fundamentalmente de invertir la perspectiva de la construcción de la nación, abandonando el camino de la tensión y de la guerra de la interpretación de Crispi y una parte de la sociedad, por el camino de la reformas: la integración mediante el pacto y el compromiso en el interior y el equilibrio y la paz como perspectiva europea y respuesta a la dicotomía de las alianzas. En la concepción del protagonista político del cambio, Giovanni Giolitti, la nueva perspectiva de la grandeza de la nación partía, pues, de la resolución en Italia del problema que planteaban las clases obreras, común a toda Europa, reconvirtiéndolas en fuerzas conservadoras del sistema en vez de fuerzas destructoras: «Solo con un tale atteggiamento ed una tale condotta da parte dei partiti costituzionali verso le classi popolari, si sarebbe ottenuto che l'avvento di queste classi, invece di essere come un turbine distruttore, riuscisse a introdurre nelle istituzioni una nuova forza conservatrice, e ad aumentare grandezza e prosperità alla Nazione» ${ }^{30}$.

Dentro de estos parámentros, ¿dónde y cómo encaja la política exterior?, ¿cual es el análisis de la situación europea? Para Giolitti la política exterior debía gozar de una cierta autonomía, pero reconocía una cierta superioridad de la política interior, de las condiciones del país. Veía la política exterior como un instrumento para protejer el crecimiento político, económico y social del país. Al mismo tiempo, la política exterior debía contribuir al equilibrio europeo como mejor garantía para la paz. De hecho, se esforzó en flexibilizar y mejorar las relaciones con Francia, aún sin perder de vista que la Triple Alianza seguía siendo el eje de la política exterior. Aspiraba a que Italia contase en Europa, a que llegase a ser, ahora como en los primeros años de Gobierno de la Destra Storica, el fiel de la balanza europea. La grandeza de Italia se mediría, en consecuencia, por el nivel de su desarrollo interno y por su capacidad de independencia en las siempre complejas 
decisiones en la esfera de las relaciones internacionales europeas. Sin embargo, mientras era acérrimo defensor de la paz en Europa a cualquier coste, admitía la posibilidad de las guerras localizadas, controlables, como las guerras coloniales, comprendidas como un mal menor y siempre que se impusieran como una inevitable necesidad ${ }^{31}$. Era contrario a la política aventurera y firme detractor del nacionalismo, que desde principios de siglo fue conformando su cuerpo ideológico hasta el nacimiento de la Associazione Nazionalista Italiana en 1910, producto, en buena medida, del crecimiento y fortalecimiento de una clase media que aumenta al calor del desarrollo económico giolittiano, y que ya no encuentra ubicación dentro del mundo liberal ${ }^{32}$. La primera prueba de fuego del proyecto giolittiano vendrá en 1911 cuando por estrictos motivos de política internacional (acuerdo franco-alemán sobre Marruecos), Italia decida -se vea «obligada» al decir de Giolitti- la ocupación de Libia. La segunda y definitiva prueba vendrá con el estallido de la Gran Guerra, cuando las esperanzas de la paz en Europa se vean definitivamente frustradas: «Sino all'ultimo avevo sperato che questa guerra, che non ha ragione e scopi da giustificare il disastro che involve sarebbe stato evitata» ${ }^{34}$.

Rota la Triple Alianza con la declaración de neutralidad italiana, el país al mando del cual se situaban ahora los liberales conservadores encabezados por Antonio Salandra y Sidney Sonnino, caminaba lentamente hacia la beligerancia que se decidió en mayo de $1915^{35}$. Salandra y Sonnino se remitían de una u otra forma al legado de Francesco Crispi, en cuanto fautor de una "gran política» para el primero, y como uno de sus estrechos colaboradores en el caso de Sonnino: «La convinzione del primato della politica estera, il sogno della piena affermazione dell'Italia come grande potenza, l'idea di consolidare il prestigio delle istituzioni con una guerra vittoriosa, li aiuteranno a superare le ultime esitazioni, anche al costo (del resto imprevisto e contrario alle loro aspettative) di indebolire e dividere il vecchio "partito liberale"» ${ }^{36}$.

\section{Nacionalismo y fascismo: la anti-Europa}

Los horrores de la Primera Guerra Mundial sacudieron las conciencias de los europeos impeliéndoles a proyectarse en un futuro de paz regido por una organización internacional, la Sociedad de Naciones, responsable en adelante de poner coto a la posibilidad de un nuevo conflicto. El nuevo clima general parecía detectar buena parte de la responsabilidad de los males pasados en los excesos de un nacionalismo alimentado durante más de cuarenta años. El final de la guerra tenía 
Italia y la perspectiva Europea:....

que servir también para acabar con ese peligro. Había que alentar -escribiría Croce- el germinar de una nueva conciencia de nación, porque las naciones no son hechos naturales, sino «stati di coscienza e formazione storiche». Desde esta reedición de la nación, Croce imagina -en una mezcla con la que probablemente Mazzini y Cattaneo se encontrarían de acuerdo- la factible construcción de Europa, siguiendo como ejemplo el camino que culminó el Risorgimento: así como un napolitano y un piamontés se hicieron italianos, sin renegar de sus raíces, «così francesi e tedeschi e italiani e tutti gli altri s'innalzeranno a europei e i loro pensieri indirizzeranno all'Europa e i loro cuori batteranno per lei come prima per le patrie piú piccole, non dimenticate ma meglio amate» ${ }^{37}$.

La primera postguerra en Italia no estaba, sin embargo, en condiciones de atenerse a ideales proyecciones europeístas. Al contrario, la guerra había dado alas a que todas las corrientes políticas de la Italia pre-bélica radicalizasen sus posturas ${ }^{38}$. En primer lugar, las fuerzas populares que habían aceptado el reformismo giolittiano, socialistas y católicos, se presentaron a la altura de 1919 como fuerzas independientes y partidos organizados (en 1919 nace el Partito Popolare), con fines propios que remarcaban de esta manera el progresivo aislamiento de la clase dirigente liberal tradicional ${ }^{39}$. Por otro lado, el nacionalismo que desde inicios de siglo se había ido constituyendo como una fuerza antireformista, por tanto antigiolittiana, antiliberal, antidemocrática y antisocialista, había llegado a elaborar en vísperas de la guerra toda una serie de teorizaciones autoritarias que condujeron, en último término, a la negación del concepto de Estado liberal y a la propuesta (Rocco) de un nuevo concepto caracterizado por subordinar todas las fuerzas del país a los intereses de la «nación», entendida como la máxima sociedad existente en el mundo pues se niega la posibilidad de una sociedad superior y más amplia que la sociedad nacional. La nación viene individuada en la clase de los «productores»: negación de la soberanía popular a cambio del Estado corporativo. Además, por el efecto de la guerra, la acción de los movimientos combatentistas, de corrientes filosóficas y de movimientos políticos y literarios de raíz irracionalista y tono revolucionario, ayudaron a crear las premisas de lo que poco después sería el fascismo ${ }^{40}$.

El mundo liberal, fracturado ya entre intervencionistas y neutralistas vuelve a dividirse de forma traumática a causa de los resultados de la paz de Versalles que buena parte de la opinión pública consideró muy inferiores al esfuerzo realizado por Italia. La frustración por la vittoria mutilata (D’Annunzio) acentúa en el caso italiano las conse- 
cuencias de la crisis económica y social característica de toda Europa, incluyendo nuevos problemas en el terreno de la política exterior como fue la ocupación militar de Fiume y la solución de apaciguamiento llevada a cabo por Giolitti, mal aceptada otra vez por una parte de la opinión pública, como fue el Tratado de Rapallo con Yugoslavia.

En marzo de 1919 nacía en Milán el movimiento de los Fasci di Combattimento dirigidos por un personaje, Benito Mussolini, que hasta noviembre de 1914 había sido uno de los exponentes principales del ala revolucionaria del Partido Socialista. A partir de entonces, se distinguió por su encendida defensa de la intervención en la guerra, creando su propio periódico, Il Popolo d'Italia. Los Fasci se presentaron con un programa revolucionario y urbano que iba desde la convocatoria de una Asamblea Constituyente, la instauración de una República, hasta la nacionalización de las industrias bélicas, la jornada laboral de ocho horas, el voto femenino, etc. De ser un movimiento poco representativo, como se demostró en las elecciones de 1919, pasó progresivamente a ir aunando consensos al ritmo que sus fuerzas paramilitares intervenían contra las acciones del movimiento obrero, tanto en el mundo rural como en las ciudades. Se presentaban, como ocurriría en otros países europeos, como una de las posibles respuestas eficaces a los problemas políticos y sobre todo sociales que la primera postguerra puso en evidencia y que el mito de la revolución en Rusia contribuyó a acentuar. Transformándose de fenómeno urbano en fenómeno rural, a finales de 1920 los fascistas, de ser un movimiento revolucionario, se habían convertido en una fuerza garante del orden. A sus filas fueron acudiendo cada vez en mayor número aquellos que había perdido la confianza en las instituciones democráticas y en la capacidad del Estado para garantizar la supervivencia del orden tradicional. Desde entonces y hasta 1922 fueron obteniendo un progresivo grado de fuerza y de representatividad política, en buena medida porque se le consideró un fenómeno pasajero, porque fue ganándose simpatías entre las filas del liberalismo conservador gracias a su antisocialismo (llegando a participar con este fin en las mismas listas electorales conformando los llamados «bloques nacionales») y porque, a pesar de sus métodos violentos, políticos de la talla de Giolitti confiaron hasta el último momento en que sería posible incorporarlos al sistema, que era factible su «constitucionalización». En noviembre de 1921 el movimiento fascista se transforma en Partito Nazionale Fascista con aspiraciones de gobierno. Apenas un año después, en octubre de 1922, la marcia su Roma determinará la toma del poder por los fascistas, en lo que a todas luces aparecía como un «compromiso» con la Corona y la vieja clase política, como demostró la conformación del primer gobierno ${ }^{41}$. 
Desde entonces y hasta 1939, punto culminante de la «fascistización» de Italia, se fue conformando progresivamente en un nuevo Estado desde presupuestos originales sin llegar a suponer, sin embargo, una total ruptura con el pasado. A comienzos de 1925 se produce un auténtico giro autoritario que precede a la construcción del régimen de partido único. Los años 1925-1929 se dedican a la construcción del régimen: el proceso es llevado a cabo gradualmente por el jurista Alfredo Rocco, a cuyo nombre están ligadas las llamadas leggi fascistissime, realizadas con el cuidado suficiente para no sobrepasar la línea de demarcación constituida por la fidelidad formal al Estatuto regio: la Monarquía -había manifestado el propio Rocco en 1914- representa la personificación viviente de la «conciencia activa de la Nación» ${ }^{42}$. La lógica de estas leyes consiste en afirmar la absoluta preminencia del ejecutivo, la liquidación del sistema parlamentario que se convierte en un mero colaborador en el ejercicio de la función legislativa y, en fin, en la consolidación de un régimen centrado en la figura del Jefe del Gobierno. Los años treinta se caracterizan, desde el perfil institucional, por la construcción del «Estado corporativo", que alcanza su momento más significativo con la creación en 1939 de la Cámara de los fascios y de las corporaciones en sustitución de la Cámara de Diputados.

La construcción del Estado totalitario se correspondía, con derivaciones tanto internas como externas, a la voluntad de potencia del fascismo mediante la reelaboración de conceptos de procedencia nacionalista e incluso liberal: el concepto de nación y el imperialismo que desde los inicios había aparecido como acción y característica del nacionalismo. Mussolini había hecho suya la idea, mezcla de Alfredo Oriani y de los nacionalistas de inicios de siglo, de que la nación se creaba con el derramamiento de sangre y que el futuro de Italia, como recitaba Oriani, estaba «tutto in una guerra, che rendendoli i confini naturali, cementi al interno, colla tragedia dei pericoli mortali, l'unità del sentimento nazionale» ${ }^{43}$. La paz perpetua -dirá Mussolini- es imposible e inútil, «solo la guerra porta al massimo di tensione tutte le energie umane e imprime un sigilo di nobiltà ai popoli che hanno virtù di affrontarla» ${ }^{44}$.

Una única voluntad nacional procurada por el estado fascista, aparecía como la mejor garantía al servicio de la expansión exterior. El terreno de la expansión imperialista venía trazado por la remisión a la herencia del Imperio Romano: el Mediterráneo. Un área que se entendía, por tanto, como de dominio «natural» de Italia, que necesitaba además territorios en los que situar sus excedentes demográficos, argumento que aparecía ya en la justificación del colonialismo por parte de Crispi y en 
los nacionalistas. Como escribirá el propio Mussolini, el Estado fascista se define como una voluntad de potencia y de imperio. Ni siquiera en los momentos en los que el dictador italiano es todavía considerado como un elemento moderado, útil al equilibrio europeo de Versalles, ceja Mussolini en sus proclamas belicistas y expansionistas. Así en 1926 manifestará que una nación que no tenga salida al Oceano no puede ser considerada una gran potencia: «'Italia deve diventare Grande Potenza» ${ }^{46}$.

La historia de la política exterior italiana durante el fascismo tiene al menos dos grandes fases separadas por la invasión de Etiopía en 1935. Hasta entonces, Italia se había comportado aparentemente como valedor del antirevisionismo alemán en Europa, garantizado en los pactos de Locarno y en su postura anti Anschluss, mientras ya desde los comienzos del régimen trabajaba por asegurarse el control del Adriático, mediante la imposición de un semi-protectorado en Albania y la amenaza constante sobre Yugoslavia. El objetivo consistía en tener la espalda cubierta para realizar el auténtico proyecto imperial que no era otro que el control del Mediterráneo con su correspondiente extensión africana. La ocupación de Etiopía era uno de los objetivos principales de la política de potencia, pues además de satisfacer el sueño imperial y extender la presencia de Italia en Africa, tenía connotaciones simbólicas importantes: era la revancha de la derrota de 1896; también la superación del mito de la vittoria mutilata, es decir la falta de resultados obtenidos con la victoria en la primera guerra mundial en el sector de la expansión colonial, y era concebida por Mussolini como el primer paso para la conquista de Egipto, Sudan y crear así un Imperio desde el Mediterráneo hasta el Índico. La condena de la Sociedad de Naciones, sostenida sobre todo por la postura de Gran Bretaña, posibilitó que el fascismo alcanzara en 1936 la más alta cota de consenso nacional. A partir de esa fecha la política exterior cambia de rumbo, se hace revisionista, se tiñe con tintes ultranacionalistas (reivindicación de territorios a Francia), y se proyecta hacia el acuerdo con Alemania como soporte de la política imperialista y eje del «nuevo orden europeo» ${ }^{48}$. El sueño de una Europa fascista o fascistizada había interesado a Mussolini desde los orígenes de su dictadura. Mediante una acción de diplomacia "paralela», intentó ganar aliados mediante la semilla de la influencia ideológica ${ }^{49}$. La guerra civil española podía llegar a cumplir el objetivo de contar con un aliado «en deuda», eficaz a la hora de llevar a cabo el anhelo mediterráneo, controlando las llaves del Mare Nostrum, y extender el Eje hasta el Atlántico.

En 1940 Mussolini creyó que había llegado la oportunidad de hacer de Italia, con la fuerza de las armas, una gran potencia mundial con 
Italia y la perspectiva Europea:....

un Imperio desde Gibraltar hasta el Oceano Índico. En cambio, desde la dramática campaña de Albania de 1940-41 el prestigio del régimen se hundió y se vió claro que el país se encaminaba hacia la catástrofe.

\section{La Europa de las impotencias: el nacimiento de la CEE}

La nación y su forma de proyectarse en la esfera internacional a través de la política de potencia, fue el obstáculo principal en el pasado para que se abriera la posibilidad a una interpretación de Europa distinta de la de terreno para la competencia. La división de Europa en bloques, la guerra fría y las necesidades estratégicas de los Estados Unidos y, en fin, la progresiva concienciación entre los Estados europeos de la imposibilidad de continuar con la política de potencias en una Europa sin grandes potencias, son factores a tener en cuenta a la hora de razonar, no solo para el caso de Italia, sobre el nacimiento y desarrollo de una política europeísta. Como ha escrito Brunello Vigezzi, «l'Italia che esce dalla seconda guerra mondiale è piuttosto e senza'altro «'impotenza» fatta persona ${ }^{50}$.

Era muy difícil en la segunda mitad de los años cuarenta pensar la esfera internacional, el marco europeo, de forma distinta a la que se había estado haciendo antes de que estallase la guerra. En el caso de Italia, la vuelta a la «normalidad» quería decir recuperar el papel internacional, las opciones, las formas diplomáticas... de $1922^{51}$.

El trabajo debía comenzar por acometer las duras condiciones del Tratado de Paz impuesto a Italia que, a pesar de los esfuerzos realizados entre 1943 y 1945, fue tratada no solo como potencia enemiga derrotada, sino como causante de la guerra. Solo una de las peticiones territoriales de Italia fue aceptada: el respeto a la frontera del Brennero. Por lo demás, Francia obtenía la modificación de su frontera en los Alpes, Istria fue entregada a Yugoslavia y Trieste fue dividida en dos zonas de ocupación, yugoslava y aliada, hasta que pasase a manos de la administración de la ONU. Además, Italia perdía todas sus colonias, cuyo futuro sería decidido por la ONU; debía reducir su ejército, no podía poseer artillería pesada, ni bombarderos, ni armas atómicas y la mayor parte de sus naves de guerra fue repartida entre los vencedores.

Se imponía de forma inmediata la tarea para volver a ser aceptado como un miembro más en la comunidad internacional. De Gasperi y Carlo Sforza como ministro de Asuntos Exteriores fueron los protagonistas de este difícil período de la historia de Italia. Es indudable que el motivo europeísta representó el argumento central de la reelaboración de la política exterior que llevó a cabo De Gasperi. Siempre 


\section{Fernando García Sanz}

con sentimiento sincero de europeísta, pero muchas veces también como motivo que equilibraba los efectos que causaba en una parte la opinión pública la dependencia de los Estados Unidos. Más que nunca política interior y política exterior se iban a ver entrelazadas: se trataba de elegir campo en una Europa dividida, un modelo político, económico y social que condicionaría a su vez la política exterior futura. Para De Gasperi la elección estaba clara: la ayuda para la reconstrucción y modernización del país sólo podía venir de Estados Unidos, así como el soporte para hacer frente a la poderosa oposición de izquierdas que representaban comunistas y socialistas. Italia se ve beneficiada por el Plan Marshall y forma parte de su órgano administrativo, la OECE, considerada por Sforza como un primer paso hacia la integración europea. Por temor a la reacción interna ante la proximidad de las elecciones del 18 de abril de 1948, en vista de la aversión de la opinión pública a los pactos militares, Italia no entró a formar parte del Pacto de Bruselas. Sin embargo, sí se adhirió a la OTAN en abril de 1949 y un mes más tarde entraba a formar parte del Consejo de Europa.

En apenas cuatro años Italia se ha liberado de su condición de enemigo derrotado y entra a formar parte como un miembro más de la comunidad internacional. Bajo la máxima de De Gasperi de apoyar cualquier propuesta que acelerase la creación de una autoridad política europea, Italia entra a formar parte de la CECA en junio de 1952. Un mes antes, De Gasperi, en París, firmaba el tratado de constitución de la Comunidad Europea de Defensa, que correspondía a una propuesta realizada en octubre de 1950 por el primer ministro francés, Pleven, siguiendo el modelo de la CECA. En 1952 De Gasperi recibe en Aquisgran el premio Carlomagno por su contribución a la unificación europea. La CED parecía el punto culminante de la aproximación franco-alemana y, por tanto, el final de uno de los más graves problemas de la postguerra. Pero el proyecto fracasa porque en 1954 la Asamblea Nacional francesa rechaza la CED.

El renovado prestigio que iba alcanzando Italia permitió que se diera satisfacción a dos cuestiones delicadas vinculadas con el Tratado de Paz: en 1950, Sforza conseguía que la ONU adjudicase a Italia la administración fiduciaria de Somalia por un período de 10 años y, en segundo lugar, Italia y Yugoslavia llegan en 1954 a un acuerdo de reparto del territorio de Trieste, que pone fin a una de las cuestiones que más había interferido en la política exterior italiana desde 1945. $\mathrm{Al}$ fracaso de la CED le sucedió casi inmediatamente el proyecto británico de transformar el Pacto de Bruselas en un acuerdo de defensa recíproca en el que entrarían a formar parte también Alemania e Italia. La llamada Unión Europea Occidental entró en funcionamiento en 1955. 
Italia y la perspectiva Europea:....

A partir de 1954 el enfrentamiento bipolar cambia su epicentro situado en el corazón de Europa, simbolizado en la cuestión del rearme alemán, para moverse fuera del continente. El Mediterráneo se va a convertir en el principal escenario del enfrentamiento entre las superpotencias y, en una dinámica convergente, de la explosión del movimiento anticolonial en Africa del Norte. En este terreno se abrían grandes posibilidades a la política exterior italiana en relación con el inmediato pasado, pues, compartiendo tesis análogas a las de Estados Unidos, eran distintas a las de otros aliados interesados en el Mediterráneo. Con respecto al mundo árabe, escribe Di Nolfo, "Il Governo di Roma mantenne in superficie un atteggiamento coerente con gli obblighi della solidarietà atlantica. Tuttavia esso sfruttò ogni canale per lasciare capire di volta in volta a Nasser, Bourghiba o ai nazionalisti marocchini che le simpatie italiane erano tutte orientate nella loro direzione, sebbene i limiti dell'influenza italiana rendessero impossibili prese di posizione esplicite ${ }^{52}$. Precisamente la crisis de Suez puso de manifiesto una cierta capacidad de autonomía de la política exterior italiana y nunca desde la segunda guerra mundial el acuerdo italo-americano había sido tan completo en el terreno diplomático. Pero la crisis de Suez parecía que iba a terminar con las esperanzas del europeísmo, debilitadas después del rechazo de la CED. Sin embargo, al contrario, el concepto de europeísmo renacía como solución a la debilidad y alternativa a la impotencia, «'Europa dei trattati di Roma nasceva in un clima quasi distratto, come rimedio a mali apparentemente inguaribili; e senza possedere un avvenire chiaramente delineato ${ }^{53}$.

Uno de los últimos libros aparecidos sobre la construcción europea, sostiene la mayor disponibilidad «natural» de los italianos a apoyar la idea de una construcción política que supere los límites nacionales, porque esta idea tiene raíces profundas en la cultura del país y, entre ellas, no son las menos importantes haber acogido y participado activamente de las dos ideas-fuerza por excelencia del universalismo: la civilización de la antigua Roma y el Cristianismo ${ }^{54}$. Sí es cierto, sin embargo, que si son reencontrables en la actualidad ideas surgidas en el pasado y resistentes a las vicisitudes históricas, una de ellas sería sin duda la idea de una Europa en paz y solidaria que surje al compás del proceso de la unidad de Italia.

\section{Notas}

1 Así, existió un Risorgimento dinástico, Saboya, y un Risorgimento garibaldino, un Risorgimento republicano unitario y otro federalista, un Risorgimento ghibellino y un Risorgimento guelfo. 
2 Mastellone, S. (1990), Historia de la democracia en Europa. De Montesquieu a Kelsen, Madrid, Edersa, p. 92, y en general el capítulo «La Nación democrática: Mazzini». Véase también a este respecto, SAITTA, A. (1971), "Lidea d'Europa dal 1815 al 1870", en Aspetti e momenti della civiltà europea, Napoli; CHABOD, F. (1967), L'idea di nazione, Bari, Laterza; "Nazione ed Europa nel pensiero dell'Ottocento", in Quaderni ACI, $\mathrm{n}^{\circ} 6$ (1951), Torino, PlumYغ̀NE, J. (1982), Le nazioni romantiche. Storia del nazionalismo nel XIX secolo, Firenze. Más concretamente sobre la relación del ideario mazziniano con respecto a Europa: Della Peruta, F. (1962), Mazzini e la giovine Europa, Milano Feltrinelli; GRIFFITH, G.O. (1935), Mazzini, profeta di una nuova Europa, Bari, Laterza; MAZzINI, G. (1850), La santa alleanza dei popoli, Roma Tip. italiana; (1984), Per l'Europa unita e federata (scritti scelti a cura di Agostino Grattarola), Roma, ENDAS; (1997) Pensieri sulla democrazia in Europa (a cura di Salvo Mastellone), Milano, Feltrinelli; TRAMAROLLO, G. (1970), Nazionalità e unità europea nel programma mazziniano, Napoli, Glaux; (1974), Mazzini e l'Europa, Atti del Convegno, Roma, Accademia nazionale dei Lincei.

3 F. Chabod (1989), Storia dell'idea d'Europa, Roma-Bari, Laterza (9ºd.), ed. a cargo de E. SESTAN y A. SAITTA, p. 133.

4 F. CHABOD (1987), p. 135.

5 R. BoNGHI, «La situazione dell'Europa e la pace», en Nuova Antologia, 16 sept. 1891, pp. 225-6, cit. por F. GHILARDI (1987), L'Europa degli equilibri, 1815-1890, Milano, Franco Angeli, p. 79.

6 Vid. F. Chabod (1990), Storia della politica estera italiana dal 1870 al 1896, Roma-Bari, Laterza ( $1^{\text {a }}$ ed. 1951), en particular el capítulo L'idea di Roma, pp. 179-323.

7 F. CHABOD (1987), p. 165.

8 F. CHABOD (1990), p. 198.

9 Seguimos en este tema las consideraciones de uno de los mejores estudios realizados hasta la fecha sobre Francesco Crispi: Umberto LEVRA (1992), Fare gli italiani. Memoria e celebrazione del Risorgimento, Torino, Comitato di Torino dell'Istituto per la Storia del Risorgimento Italiano. En particular el capítulo «Il Risorgimento nazional-popolare di Crispi", pp. 299-386.

10 LeVRA (1992), p. 340.

11 LEVRA (1992), p. 316.

12 Sergio Romano (1994), Disegno della storia d'Europa dal 1789 al 1989, Milano, TEA, p. 81 .

13 Remito, además de los citados anteriormente, a la siguiente bibliografía de caracter general: L. SALVATORELli (1939), La Triplice Alleanza. Storia diplomatica (18771912), Milano, ISPI; G. SALVEMINI (1944), La politica estera dell'Italia dal 1871 al 1914, Firenze, Barbèra; A. TORRE (1959-1960), La politica estera italiana (1870-1914), Bologna, Zanicheli, 2 vols.; R. PETRIGNANi (1987), Neutralità ed alleanza. Le scelte di politica estera dopo l'unità, Bologna, Il Mulino; E. DECleva (1987), L'incerto alleato. Ricerche sugli orientamenti internazionali dell'Italia unita, Milano, Franco Angeli.

14 Dentro del debate general sobre la política exterior que debía seguir Italia durante estos años, quizás la voluntad de construir una política exterior liberal sea el esfuerzo más reseñable y debido, sobre todo, al trabajo de Emilio Visconti Venosta, protagonista de la elaboración de la política exterior de la Destra Storica. Dentro de las grandes dificultades tanto internas como externas, se asentaron una serie de principios sólidos que tuvieron continuidad en el tiempo hasta 1914: la necesidad de una política de equilibrio, el deseo de paz para Europa bajo cualquier circunstancia y... el reconocimiento del status de gran potencia a Italia. Un concepto de gran potencia 
que, a diferencia del período inmediatamente siguiente, venía entendida aún en términos de la primera mitad del siglo XIX, es decir como independencia de criterio y capacidad de influencia sobre los grandes asuntos europeos. Véase un magnífico análisis de este tema en B. VIGEZZI (1991), «iberalismo e politica estera", en R.J.B. BoswORTH y S. Romano, La politica estera italiana (1860-1985), Bologna, Il Mulino, pp. 231-286.

15 Sobre la relación de Crispi y el colonialismo, R. BATTAGLIA (1958), La prima guerra d'Africa, Torino, Einaudi. Un resumen de las vicisitudes coloniales de Italia en F. García SANZ (1994), Historia de las relaciones entre España e Italia. Imágenes, Comercio y política exterior (1890-1914), Madrid, CSIC y "I "Paesi latini" e le crisi coloniali di fine Ottocento", en A.A. MolA (1998), L'Italia nella crisi dei sistemi coloniali fra Otto e Novecento, Foggia, Bastogi, pp. 17-67.

16 Sobre el debate historiográfico en torno al colonialismo italiano y, en concreto, a la primera campaña de Etiopia véase el resumen, al hilo del centenario de la derrota de Adua, que realiza Paolo FERRARI (1996), "Adua centenario rimosso. Il colonialismo italiano dell'Ottocento", en Italia Contemporanea, 205, pp. 737-743.

17 LEvRA, U., (1992) pp. 314-315.

18 Fue publicado en París, en cuatro volúmenes, entre 1853-1855. Significativamente, en 1884 vería la luz la segunda edición y la traducción española no se haría hasta 1937: Ensayo sobre la desigualdad de las razas humanas, Barcelona, Apolo.

19 Gobineau viene a equiparar "semitización" con degeneración de la raza blanca. A pesar de que el texto de Gobineau fue ampliamente utilizado en Alemania como soporte a las teorías racistas (en 1898 se tradujo al alemán), el autor pone de manifiesto recurrentemente que no existe la raza pura: «la familia aria y, con mucha más razón, el resto de la familia blanca, había cesado de ser absolutamente pura en la época en que nació Jesucristo" (p. 638).

20 Ibid., pp. 36-37.

21 Ibid. pp. 52-53.

22 Ibid., p. 118.

23 Vid. a este respecto, FIELD, G.G. (1981), Evangelist of Race. The Germanic Vision of Houston Stewart Chamberlain, New York, Columbia University Press. Field pone de manifiesto que fue Ludwig Schemann el introductor, traductor y publicista de Gobineau en la Alemania de finales de siglo llegando a crear, en 1894, el Gobineau Vereinigung como centro de culto del autor francés. Vid. en particular el capítulo «The Bayreuth Publicist», pp. 123-168.

24 PESET, J.L y PESET, M., (1975) Lombroso y la escuela positivista italiana, Madrid, CSIC, p. 28

25 FERrero, G. (1897) L'Europa giovane: studi e viaggi nei paesi del Nord, Milano, Treves. Se conocen otras tres ediciones de este libro en 1898, 1903 y 1946. Un Ferrero a favor de la intervención de Italia en la Primera Guerra Mundial, escribirá en 1917 Le genie latin et le monde moderne, Paris, Grasset.

26 Véanse sobre este aspecto los escritos del propio FERRERo, G. (1894), Il fenomeno Crispi e la crisi italiana, Torino, C. Olivetti; (1924), Le dittature in Italia: Depretis, Crispi, Giolitti, Mussolini, Milano, Corbaccio. Sobre el debate en torno a la pervivencia de los ideales del Risorgimento en la historia de Italia, vid. el número monográfico (1995) Il mito del Risorgimento nell'Italia unita, en Il Risorgimento. Rivista di Storia del Risorgimento e di Storia Contemporanea, a. XLVII. n. 1-2, Milano.

27 CROCE, B. (1921), Storia della Storiografia italiana nel secolo decimonono, Bari, Laterza, 1921, II Vols, vol. 2?, pp. 242-243. 
28 Colajanni, N. (1898), Settentrionali e meridionali: agli italiani del Mezzogiorno, Milano-Palermo, Biblioteca della Rivista Popolare; (1903), Razze inferiori e razze superiori: Latini e Anglo-sassoni, Roma, La Rivista Polpolare Ilustrata; SERGI, G (1901), La decadencia de las naciones latinas, Barcelona, Biblioteca Moderna de Ciencias Sociales.

29 Cit. en García SANZ, F. (1994), pp. 204 y ss.

30 GiolitTi, G. (1982), Memorie della mia vita, Milano, Garzanti (1? ed., 1922). Un análisis de conjunto sobre el período giolittiano en CANDELORO, G. (1981), La crisi di fine secolo e l'età giolittiana, vol. VII de la Storia d'Italia, Milano, Feltrinelli; CAROCCI, G. (1971), Giolitti e l'età giolittiana. La politica italiana dall'inizio del secolo alla prima guerra mondiale, Torino, Einaudi; GENTILE, E. (1990), L'Italia giolittiana, Bologna, Il Mulino.

31 La elaboración de estos párrafos a partir de las consideraciones de VIGEzZI, B. (1991), pp. 282 y ss.

32 Gentile, E. (1990), p. 232.

33 Sobre el debate historiográfico en torno a la guerra de Libia, VIGEZZI, B. (1980), "Limperialismo e il suo ruolo nella storia italiana del primo novecento", en Storica Contempranea, febrero, pp. 29-56.

34 VigezZI, B. (1991) p. 284.

35 Sobre el progresivo camino de Italia hacia la guerra, sobre el debate entre intervención y neutralidad, y sobre la excisión del mundo político italiano, VIGEZZI, B. (1966), L'Italia di fronte alla guerra mondiale, vol. I, L'Italia neutrale, Napoli, Ricciardi; Cfr. Tranfaglia, N. (1981), Dallo stato liberale al regime fascista, Milano, Feltrinelli.

36 VigeZZI, B. (1991), pp. 285-286.

37 Croce, B. (1932), Storia d'Europa nel secolo decimonono, (3? ed. riveduta), Bari, Laterza, p. 358.

38 Para un encuadre general del período, CHABOD, F. (1961), L'Italia contemporanea (1918-1948), Torino, Einaudi; GAETA, F. (1989), Democrazia e totalitarismi dalla prima alla seconda guerra mondiale (1918-1945), Bologna, Il Munlino; PERFETTI, F. (1978 y 1980), L'Italia fra le due guerre, vols. III y IV de la Storia dell'italia contemporanea, dirig. por R. De Felice, Napoli, ESI; TRANFAGLIA, N. (1995), La prima guerra mondiale e il fascismo, vol. XXII de la Storia d'Italia, dirig. por G. Galasso, Torino, UTET.

39 Sobre la historia del movimiento católico, DE RosA, G. (1966), Storia del movimento cattolico, Bari, Laterza; Scoppola, P. (1957), Dal neoguelfismo alla Democrazia Cristiana, Roma, Studium. Sobre la historia del socialismo italiano, ARFÉ, G. (1965), Storia del socialismo italiano, 1892-1926, Torino, Einaudi; CoRTESI, L. (ed) (1969), Il socialismo italiano tra riforme e rivoluzione, Bari, Laterza.

40 Sobre el nacionalismo italiano, Cfr. GAETA, F. (1981), Il nazionalismo italiano, Bari, Laterza; D’oRSI, A. (ed) (1981), I nazionalisti italiani, Milano, Feltrinelli; PERFETTI, F. (ed) (1977), Il nazionalismo italiano dalle origini alla fusione con il fascismo, Bologna, Capelli; por último, a pesar de que ha sido una tesis muy discutida, sigue siendo obra de referencia el trabajo de Salvatorelli, L. (1977), Nazionalfascismo, Torino, Einaudi ( $1^{\circ}$ ed. 1923).

41 Algunas obras generales sobre la historia del fascismo además de las ya citadas, Milza, P. \& Berstein, S. (1982), Storia del fascismo, Milano, Rizzoli; DE Felice, R (1965), Mussolini il rivoluzionario 1883-1920, Torino Einaudi; (1966-1986) Mussolini il fascista, 1921-1929, 2 tomos, Torino, Einaudi; (1969) Le interpretazioni del fascismo, Bari Laterza; (1974-1981) Mussolini il Duce (1929-1940), Torino, Einaudi; GENTILE, E. (1975), Le origini dell'ideologia fascista, Bari, Laterza; PAYNE, S.G (1982), El fascismo, 
Madrid, Alianza Editorial; Perfetti, F. (1988), Fiummanesimo, sindacalismo e fascismo, Roma, Branca; Veneruso, D. (1981), L'Italia fascista, Bologna, Il Mulino.

42 Perfetti, F. (1977), p. 33.

43 Citado en Knox, M. (1991), "Il fascismo e la politica estera italiana», en BOSWorTh, R.J.B e ROMANO, S., op. cit., p. 292.

44 Tranfaglia, N. (1995), p. 454.

45 Ibidem. Sobre la idea de Imperio en Mussolini y su papel en la política exterior, RUMI, G. (1968), Alle origini della politica estera fascista (1918-1923), Bari, Laterza.

46 Ibid., p. 396. La gran potencia a la que aspiraba Mussolini era muy distinta de la que se trataba en el siglo XIX. Sobre los elementos de continuidad y ruptura que representa la política exterior fascista en la historia de Italia, véase el breve esquema trazado por KNOX (1991), pp. 328-329.

47 Para un encuadre de la política exterior durante el fascismo véanse además de las obras ya citadas: DI NolFo, E. (1960), Mussolini e la politica estera italiana (1919-1933), Padova, CEdAM; DE FELICE, R. (ed) (1973), L'Italia fra tedeschi e alleati. La politica estera fascista e la seconda guerra mondiale, Bologna, Il Mulino; PASTORELLI, P. (1971), "La storiografia italiana del dopoguerra sulla politica estera fascista", in Storia e Politica, a. X, n. 4; QuARTARARo, R. (1980), Roma tra Londra e Berlino. La politica estera fascista dal 1930 al 1940, Roma, Bonacci.

48 La obligación de realizar un breve apunte no permite entrar en otras valoraciones que, sin embargo, serían muy necesarias. Por ejemplo, la necesidad de subrayar que la perspectiva de una "inevitable" alianza de Italia con Alemania está presente en Mussolini incluso antes de la conquista del poder como subraya KNOX (1991), pp. 304 y ss.

49 Sobre este tema, BoREJSZA, J.W. (1981), Il fascismo e l'Europa orientale. Dalla propaganda all'aggressione, Roma-Bari, Laterza; ColloTI, E.(1989), Fascismo, fascismi, Firenze, Sansoni; LedeEn, M. (1972), L'internazionale fascista, Bari, Laterza; SAZ, I. (1986), Mussolini contra la II República (1931-1936), Valencia, Edicions Alfonso El Magnanim; (1996) "Les peculiaritats del feixisme espanyol», en Afers, 25, pp. 623-637.

50 VigEZZI, B. (1988), «De Gasperi, Sforza, la diplomazia italiana e la politica di potenza dal trattato di pace al patto atlantico", en DI NolFo, E., RAINERO, R.H. y VigEZZI, B. (eds.) L'Italia y la politica di potenza in Europa (1945-1950), Milano, Marzorati, pp. 3-57.

51 Como obras de referencia para este período, CACACE, P. (1988), Vent'anni di politica estera italiana (1943-1963), Roma, Bonacci; DI NolFo, E., RAINERO, R.H. y VIGEZZI, B. (eds.) (1992), L'Italia e la politica di potenza in Europa (1950-1960), Milano, Marzorati; PASTORELli, P. (1987), La politica estera italiana del dopoguerra, Bologna, Il Mulino; Seton-Watson, Ch. (1991), "La politica estera della Repubblica italiana», en Bosworth, R.J.B., Romano, S. (1991), op. cit., pp. 331-360. Sobre la historia del protagonismo de Italia en el proceso de integración europea, abordado desde numerosos puntos de vista, es muy útil el número monográfico (1998-1999) L'Italia e il processo di integrazione europea: prospettive di ricerca e revisione storiografica coordinado por Antonio Varsori, de la Revista Storia delle Relazioni Internazionali, a. XIII/2-a. XIV/1.

52 Di Nolfo, E. (1992), "La "politica di potenza" e le formule della politica di potenza. Il caso italiano (1952-1956)», en E. Di NOLFO, R.H. RAINERO y B. VigEzZI (eds.), op. cit., p. 717.

53 Ibid., p. 723.

54 PADOA-SCHIOPPA, T. (2001), Europa, forza gentile, Bologna, Il Mulino. En particular el capítulo "Italia europea, Europa italiana». 